\title{
Improving family planning service delivery in humanitarian crises
}

Chi-Chi Undie

Population Council

Rajat Khosla

Karl Blanchet

Follow this and additional works at: https://knowledgecommons.popcouncil.org/departments_sbsr-rh

Part of the Community Health and Preventive Medicine Commons, Demography, Population, and Ecology Commons, Family, Life Course, and Society Commons, International Public Health Commons, and the Women's Health Commons

How does access to this work benefit you? Let us know!

\section{Recommended Citation}

Undie, Chi-Chi, Rajat Khosla, and Karl Blanchet. 2017. "Improving family planning service delivery in humanitarian crises," Family Planning Evidence Brief. Geneva: World Health Organization. 


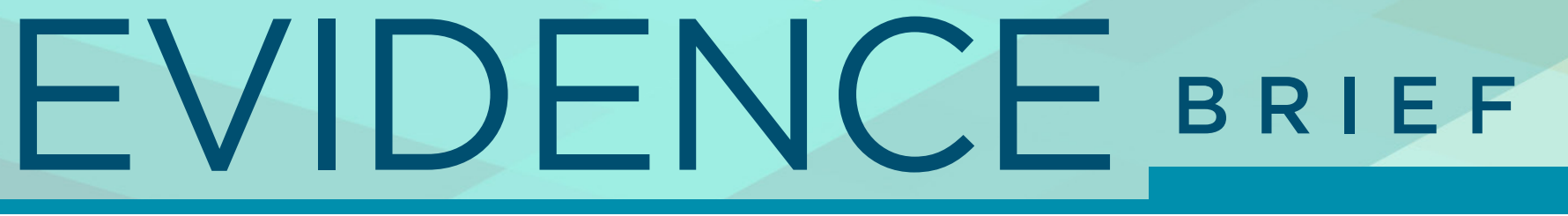

\section{Improving family planning service delivery in humanitarian crises}

\section{$\rightarrow$ Meeting family planning needs in humanitarian emergencies is challenging, but feasible, and could present opportunities for reaching marginalized, remote, or otherwise underserved populations.}

Since the 2012 London Summit on Family Planning, 30 million additional women and girls have chosen to use modern contraception. This means that in 2016, we reached a landmark as some 300 million women and girls in the world's poorest countries were using modern methods of contraception (1). But 2016 also saw another landmark reached: the highest number of forcibly displaced people in recorded history (2).

Described as a sudden occurrence caused by epidemics, technological or environmental catastrophe, strife, or natural/man-made causes and demanding immediate action (3), humanitarian crises have caused a dramatic rise in the number of displaced populations, both within and across national borders. In 2016, 65.3 million individuals were considered to be internally displaced people and international migrants (2), with the average time spent in displacement being currently up to 20 years (2). Humanitarian crises expose weaknesses in health systems, with particularly serious consequences for women, children and adolescents (4).

From 2003 to 2015, the proportion of women among refugees held steady at between $47 \%$ and $49 \%$, while the proportion of refugees who were children below 18 years of age increased from 41\% in 2009 to $51 \%$ in 2015 (4). Globally, the estimated 26 million women and girl refugees are affected disproportionately by emergencies and face multiple sexual and reproductive health (SRH) risks, requiring access to key services, including contraception (5). With the disruption of protection services, sexual violence often increases during emergencies to affect about 1 in 5 women (6), exacerbating threats to the health and survival of women and girls. The situation is further aggravated by the lack of access to emergency contraception (7) as highlighted in a recent review by the Inter-Agency Working Group on Reproductive Health in Crises (8). Furthermore, 12 of the 13 countries with the lowest prevalence of modern contraceptive use in 2016 are 'fragile states' (9). The reality of sexual

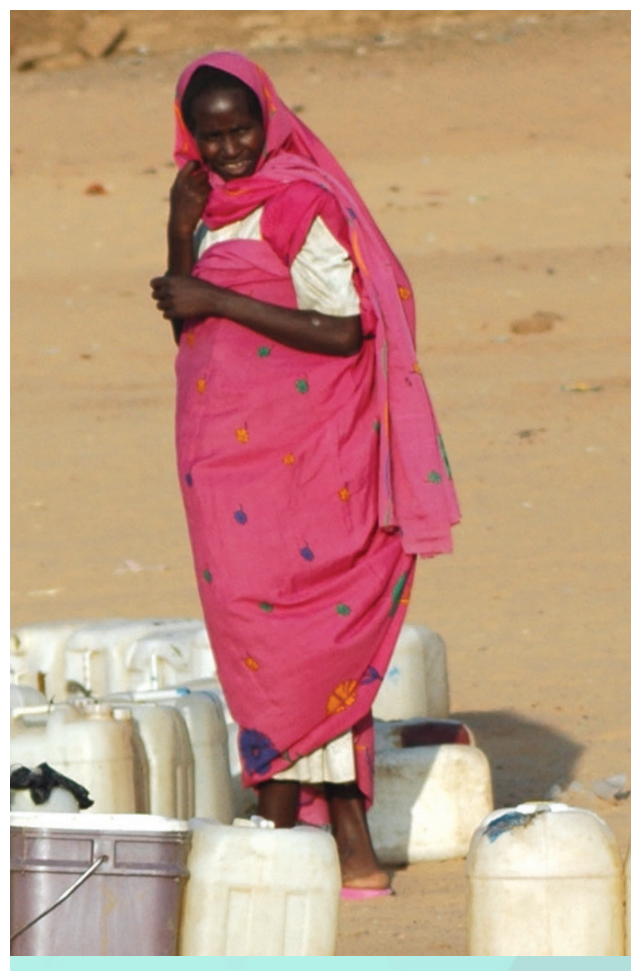

\section{POLICY AND PROGRAM CONSIDERATIONS}

$\rightarrow$ Provide a full range of family planning methods via mobile clinics and strengthen health centres' provision of short- and long-acting methods.

$\rightarrow$ Train mobile health workers to provide short-acting methods.

$\rightarrow$ Train community health workers to conduct family planning education and provide shortacting methods. 
violence in humanitarian settings heightens the need to expand access to emergency contraception, long-acting reversible contraception (LARCs), and safe abortion services.

\section{POSSIBILITIES}

Meeting family planning needs in humanitarian emergencies is challenging but feasible, and could present opportunities for reaching marginalized, remote, or otherwise underserved populations. Young people in such settings are usually new users of contraception and could initiate contraceptive use that continues into adulthood (10). Where humanitarian assistance is delivered in encamped spaces, this structure could facilitate the provision of family planning services and information (11). In camp settings specifically, the process of resettling displaced persons requires communication of health information to underserved populations (11,12), and there are openings for integrating family planning information and services into such processes.

\section{CHALLENGES AND LESSONS LEARNED}

Nonetheless, there is a lack of evidence and high-quality routine data related to family planning in crises (13). Little is known about the context of family planning in humanitarian settings (14): its availability and use; attitudes and barriers to the use of various contraceptive methods; and the extent and context of emergency contraception use following sexual violence (15).

In the absence of a clear accountability and monitoring framework for $\mathrm{SRH}$ (including family planning) in humanitarian crises, available data are derived from specific studies. The sparse evidence demonstrates a need for the increased uptake of emergency contraception to mitigate rape-related pregnancy (7). Further, when family planning services are available and accessible, women's use of family planning has increased (13).

Still, gaps remain in regard to how to implement family planning interventions in humanitarian situations. Evidence exists from stable settings on effective family planning interventions (13), even if evidence on how to deliver such interventions in these settings is often inconclusive (16). Higher-quality evidence on family planning in emergencies through a common accountability framework is needed to improve access to voluntary family planning services in humanitarian settings. Providing greater access could make a substantial contribution to the achievement of the FP2O20 goals.
CONSIDERATIONS FOR IMPROVING

FAMILY PLANNING SERVICE DELIVERY IN HUMANITARIAN CRISES

In the context of humanitarian crises, several promising, evidence-based interventions for family planning service delivery can help improve the uptake of these services (17). These interventions are summarized as follows:

- Provide comprehensive SRH services in line with global norms, such as the Minimum Initial Service Package (MISP) for Reproductive Health in Crisis Situations (18).

- $\quad$ Provide a full range of family planning methods via mobile clinics and strengthen health centres' provision of short- and long-acting methods (19).

- Train mobile health workers to provide short-acting methods (20).

- $\quad$ Second refugee providers to health facilities to provide family planning in humanitarian settings, and train female community health workers (CHWs) to promote FP use (21).

- Train CHWs to conduct FP education and provide short-acting methods (22).

- Collaborate with the Ministry of Health on competency-based training, supply chain management, systematic supervision, and community mobilization to raise awareness and alter family planning norms (23).

- Engage adolescents through (24):

- Family planning counselling and referrals, coupled with recreational activities and group discussions.

- Delivery of youth-friendly SRH care and education via clinics, mobile health brigades, and community education.

- Provision of SRH information and services through a comprehensive prevention approach, combining 'Talk,' 'Services,' and 'Livelihoods.' 


\section{REFERENCES}

1 Scoggins \& Bremner (2016). FP2O20 momentum at the midpoint 2015-2016. http://progress.familyplanning2020. org/.

2 UNHCR (2015). Global trends: Forced displacement in 2015. http://www.unhcr.org/576408cd7.

3 Inter-Agency Standing Committee (1994). WHO Definition of Emergency.

4 Zeid, K. Gilmore, R. Khosla et al. (2015). Women's, children's and adolescents' health in humanitarian and other crises. BMJ 2015;351:h4346.

5 Askew, Khosla et al. (2016). Sexual and reproductive health and rights in emergencies. Bulletin of the World Health Organization (94):311.

$6 \mathrm{Vu}$, Adam, Wirtz et al. (2014). The prevalence of sexual violence among female refugees in complex humanitarian emergencies: A systematic review and meta-analysis. PLOS Current Disasters 1.

7 Undie, Birungi et al. (2016). Effectiveness of a communitybased SGBV prevention model in emergency settings in Uganda: Testing the 'Zero Tolerance Village Alliance' intervention. Nairobi, Kenya: Population Council.

8 Inter-Agency Working Group on Reproductive Health in Crises. Global Evaluation 2012-2014. Available at http:// iawg.net/resource/iawg-global-evaluation-2012-2014/.

9 FP2O2O. (2016). Track 20 report 2016.

10 Tanabe et al. (2017). Family planning in refugee settings: Findings and actions from a multi-country study. Conflict and Health 11 (9).

11 Murshid (2013). The politics of refugees in South Asia: Identity, resistance, manipulation. New York and London: Routledge.

12 Morand (2015). Urban humanitarians: A new breed needed. In MacGinty \& Peterson (eds.). The Routledge Companion to Humanitarian Action.

13 Warren et al. (2015). Systematic review of the evidence on the effectiveness of sexual and reproductive health interventions in humanitarian crises. BMJ Open (5): e008226. doi:10.1136/ bmjopen-2015-008226.

14 Blanchet et al. (2017). Evidence on public health interventions in humanitarian crises. June. Lancet.

15 WHO (2017). Technical consultation for research on sexual and reproductive health and rights in humanitarian settings: Meeting summary, February 1-2, 2017, p. 3.

16 Mwaikambo et al. (2011). What works in family planning interventions: A systematic review. Studies in Family Planning 42:67-82.

17 Casey, S. (2015). Evaluations of reproductive health programs in humanitarian settings: A systematic review. Conflict and Health 9 (Supp 1)S1.

18 Minimum Initial Service Package for Reproductive Health in Crisis Situation: A Distance Learning Module. Available at http://www.unhcr.org/4e8d6b3b14.pdf

19 Casey et al. (2013). Availability of long-acting and permanent family-planning methods leads to increase in use in conflict-affected northern Uganda: Evidence from cross-sectional baseline and endline cluster surveys. Global Public Health 8:284-297.
20 Mullany et al. (2015). Impact of Community-Based Maternal Health Workers on Coverage of Essential Maternal Health Interventions among Internally Displaced Communities in Eastern Burma: The MOM Project. PLoS Medicine 2010, 7:e1000317.

21 Howard et al. (2008). Reproductive health services for refugees by refugees in Guinea I: family planning. Conflict and Health 2:12.

22 Huber D, Saeedi N, Samadi AK. (2010). Achieving success with family planning in rural Afghanistan. Bulletin of the World Health Organization 88:227-231.

23 Curry et al. (2015). Delivering high-quality family planning services in crisis-affected settings II: Results. Global Health: Science and Practice 3(1):25-33.

24 Women's Refugee Commission, Save the Children, UNHCR, UNFPA (2012). Adolescent sexual and reproductive health programs in humanitarian settings: An in-depth look at family planning services.

Authors: Chi-Chi Undie, Population Council; Rajat Khosla, World Health Organization; Karl Blanchet, London School of Hygiene and Tropical Medicine.

This is one of seven Family Planning Evidence Briefs prepared for the Family Planning Summit held in London on July 11, 2017. The briefs highlight evidence and provide research and programme considerations for improving access to family planning and reducing unintended pregnancy. Programme considerations are based on the expert views of the authors, who undertook desk reviews drawing on existing evidence.

\section{Family Planning Evidence Briefs}

- Accelerating uptake of voluntary, rights-based family planning in developing countries (overview)

- Ensuring adequate financing of family planning commodities and services

- Reducing early and unintended pregnancies among adolescents

- Improving family planning service delivery in humanitarian crises

- Ensuring contraceptive security through effective supply chains

- Expanding contraceptive choice

- Partnering with the private sector to strengthen provision of contraception

The authors alone are responsible for the views expressed in this article and they do not necessarily represent the views, decisions or policies of the institutions with which they are affiliated.

Family Planning Evidence Brief - Improving family planning service delivery in humanitarian crises: WHO/RHR/17.13

(c) World Health Organization 2017. Some rights reserved. This work is available under the CC BY-NC-SA 3.0 IGO license.

For more information, please contact: Department of Reproductive Health and Research, World Health Organization, Avenue Appia 20, $\mathrm{CH}-1211$ Geneva 27, Switzerland

E-mail: reproductivehealth@who.int

Website: www.who.int/reproductivehealth

Twitter: @HRPresearch

This material has been funded by UK aid from the UK government; however, the views expressed do not necessarily reflect the UK government's policies.

Prepared July 2017 